\title{
Clinical observation of ulinastatin combined with CRRT in the treatment of early cardiopulmonary resuscitation
}

\author{
QINGHONG LIU, JINLIANG PENG, YUMING ZHOU, WEILAN ZENG, SHIHUI XIAO, HUI CHENG, \\ ZHENZHOU ZHONG, XIANGMING LIAO, XIAOLIU XIAO, LIANG LUO and XIANGHONG LIU
}

Department of Emergency, Ganzhou People's Hospital, Ganzhou, Jiangxi 341000, P.R. China

Received June 28, 2017; Accepted October 10, 2017

DOI: $10.3892 / \mathrm{etm} .2017 .5325$

\begin{abstract}
The clinical efficacy of ulinastatin (UTI) combined with continuous renal replacement therapy (CRRT) in the treatment after early cardiopulmonary resuscitation (CPR) was evaluated. A total of 70 patients who were successfully treated with CPR in Ganzhou People's Hospital from October 2016 to March 2017 were selected as the subjects. The patients were randomly divided into control group (35 cases, conventional treatment) and UTI combined with CRRT group (35 cases, UTI + CRRT). The whole blood of patients was collected at $0,3,6$ and $12 \mathrm{~h}$ after CPR. Reverse transcription-polymerase chain reaction assay was used to detect the changes of tolllike receptor 4 (TLR4) gene in mRNA levels between the two groups, i-STAT system 300 was used to analyze $\mathrm{pH}$ level, $\mathrm{SO}_{2}$, $\mathrm{HCO}_{3}{ }^{-}$and lactic acid (LAC) concentration; Abbott AXSYM system was used to detect the expression of cardiac troponin I (cTnI) in serum; the concentration of plasma malondialdehyde (MDA) was examined by a special kit; interleukin-6 (IL-6) and tumor necrosis factor- $\alpha$ (TNF- $\alpha$ ) in patients was determined by enzyme-linked immunosorbent assay. The effect of UTI combined with CRRT in the early stage of CPR was analyzed. The levels of TLR4, cTnI, TNF- $\alpha$, IL- 6 and MDA in the plasma of patients in both groups were significantly increased $(\mathrm{P}<0.05)$, but the expression level in UTI + CRRT group was lower than that in control group $(\mathrm{P}<0.05)$. Compared with the control group, the $\mathrm{HCO}_{3}{ }^{-}$decreased significantly $(\mathrm{P}<0.05)$ in the UTI + CRRT group at $3 \mathrm{~h}$, while the $\mathrm{pH}$ and $\mathrm{SO}_{2}$ did not change significantly. UTI + CRRT could significantly shorten the average recovery time of consciousness and the average recovery time of consciousness and spontaneous respiration in patients treated with $\mathrm{CPR}(\mathrm{P}<0.05)$. Moreover, the score of APACHE II was significantly lower than that of control
\end{abstract}

Correspondence to: Dr Xianghong Liu, Department of Emergency, Ganzhou People's Hospital, 17 Hongqi Avenue, Ganzhou, Jiangxi 341000, P.R. China

E-mail: liuqinghongdr@163.com

Key words: ulinastatin, continuous renal replacement therapy, cardiopulmonary resuscitation group $(\mathrm{P}<0.05)$. UTI combined with CRRT treatment can significantly improve the patient's condition after early CPR.

\section{Introduction}

Sudden cardiac death is the leading cause of death in the world. Statistics show that in China, the number of sudden cardiac death per year is 544,000 (1). Cardiopulmonary resuscitation (CPR) is the most effective way to save the lives of patients. However, CPR still failed to achieve satisfactory results in the treatment of cardiac arrest $(\mathrm{CA})$. The literature reported that $40 \%$ of patients undergoing CPR treatment achieved return of spontaneous circulation (ROSC), 10-30\% of patients were completely cured and discharged, and the remaining patients died of disease (2). However, patients with successful rescue can often have a variety of complications, such as permanent neurological complications, including cognitive disorders and dyskinesia (3); post-resuscitation cardiac dysfunction is also an important reason leading to poor prognosis of patients (4), it manifests as systemic ischemia and reperfusion syndrome. At the same time, due to the sharp increase of a variety of deregulation cytokines in the blood $3 \mathrm{~h}$ after CA, such as endotoxin releasing into the plasma, there will be severe sepsis, leading to tissue damage (5-7). Therefore, it is of important clinical significance to explore an effective treatment in order to improve the CPR postoperative prognosis.

In this experiment, we selected ulinastatin (UTI). UTI is derived from human urinary protease inhibitors (8). It has been proved to have anti-inflammatory, inhibiting neutrophil elastase, inhibiting chemokine release and penetration effects (9). In addition, UTI protects mitochondrial function by reducing calcium overload in cells, playing a role in the protection of heart, lung, liver, kidney ischemia-reperfusion injury (10). However, few studies have evaluated the effect of UTI on cardiac dysfunction after CPR. In the present study, we adopted continuous renal replacement therapy (CRRT) at the same time, analyzed the role of UTI + CRRT in early CPR, to provide some theoretical basis for clinical treatment and improving the prognosis of CA.

\section{Materials and methods}

Clinical data. A total of 70 patients who were treated for CPR in Ganzhou People's Hospital from October 2016 to March 
2017 were selected as the subjects. All patients or their families signed informed consent, all procedures were in accordance with the principles set out in the Helsinki Declaration. A total of 70 patients were randomly divided into control group ( $n=35$, male 18 , female 17 , mean age: $53.71 \pm 5.41$ years) and UTI combined with CRRT group (UTI + CRRT, $n=35$, male 19, female 16, mean age: $54.64 \pm 14.72$ years). According to the American Heart Association guidelines, CPR was performed, if necessary, chest compression and defibrillation was given in reference to Advanced Cardiac Life Support Protocol. The study was approved by the Ethics Committee of Ganzhou People's Hospital.

Successful recovery was defined as patients showing significant pulse and electrocardiography rhythm as well as ventricular tachycardia or fibrillation. In the control group, patients were treated with conventional symptomatic therapy. In the UTI + CRRT group, patients were treated with intravenous injection of UTI immediately after ROSC (Guangdong Tianpu Biochemical Pharmaceutical Co., Ltd., Guangzhou, China; SFDA approval no. H9990134) (300,000 U dissolved in $20 \mathrm{ml} \mathrm{NaCl}$ solution), once every $12 \mathrm{~h}$. At the same time, CRRT treatment was performed with Diapact CRRT (B. Braun Melsungen AG, Melsungen, Germany), 3 times for each patient: Once per day for 3 days, $8 \mathrm{~h}$ for each treatment. All patients underwent preoperative and post-resuscitation APACHE II scoring by the same physician.

Sample collection and testing. The whole blood samples of the patients were collected at 4 time points $(0,3,6$ and $12 \mathrm{~h}$ ) after CPR. After collecting them in the sodium citrate anticoagulant tube, the cells were centrifuged for $5 \mathrm{~min}$ at $1,500 \mathrm{x}$ g, then preserved at $-80^{\circ} \mathrm{C}$ immediately. After all the samples were collected, tumor necrosis factor- $\alpha$ (TNF- $\alpha$ ), IL-6, malondialdehyde (MDA) and cardiac troponin I (cTnI) were measured in all samples. Blood samples from patients were analyzed for $\mathrm{pH}, \mathrm{SO}_{2}, \mathrm{HCO}_{3}{ }^{-}$and lactic acid (LAC) using i-STAT System 300 (Abbott Laboratories Inc., NY, USA). The cTnI concentration was measured using the Abbott AXSYM system. The MDA content was determined by the kit (Sigma; Merck KGaA, Darmstadt, Germany).

Detection of serum TNF- $\alpha$ and IL- 6 by ELISA. The levels of TNF- $\alpha$ and IL- 6 in the serum of the patients were determined by the ELISA kit (Abcam, Cambridge, MA, USA). The reaction was carried out according to the kit instructions. The reaction product was measured at $450 \mathrm{~nm}$ wavelength and the OD values were measured, the expression was analyzed.

Detection of toll-like receptor 4 (TLR4) expression by RT-PCR. The lymphocytes in the blood were extracted using the TBD lymphocyte extraction kit (Tiangen Biotech Co., Ltd., Beijing, China), and RNA was extracted using TRIzol reagent (Invitrogen; Thermo Fisher Scientific, Inc., Waltham, MA, USA). The concentration of extracted RNA was measured using a spectrophotometer, $1 \mu \mathrm{g}$ of RNA was taken for reverse transcription (Takara Bio, Inc., Otsu, Japan). The mRNA levels of each indicators were determined using SYBR-Green fluorescent reagent (Toyobo Life Science, Osaka, Japan). TLR4 gene primers were synthesized by Sangon Biotech Shanghai Co., Ltd. (Shanghai, China). Sequences: Upstream 5'-CGTCTA
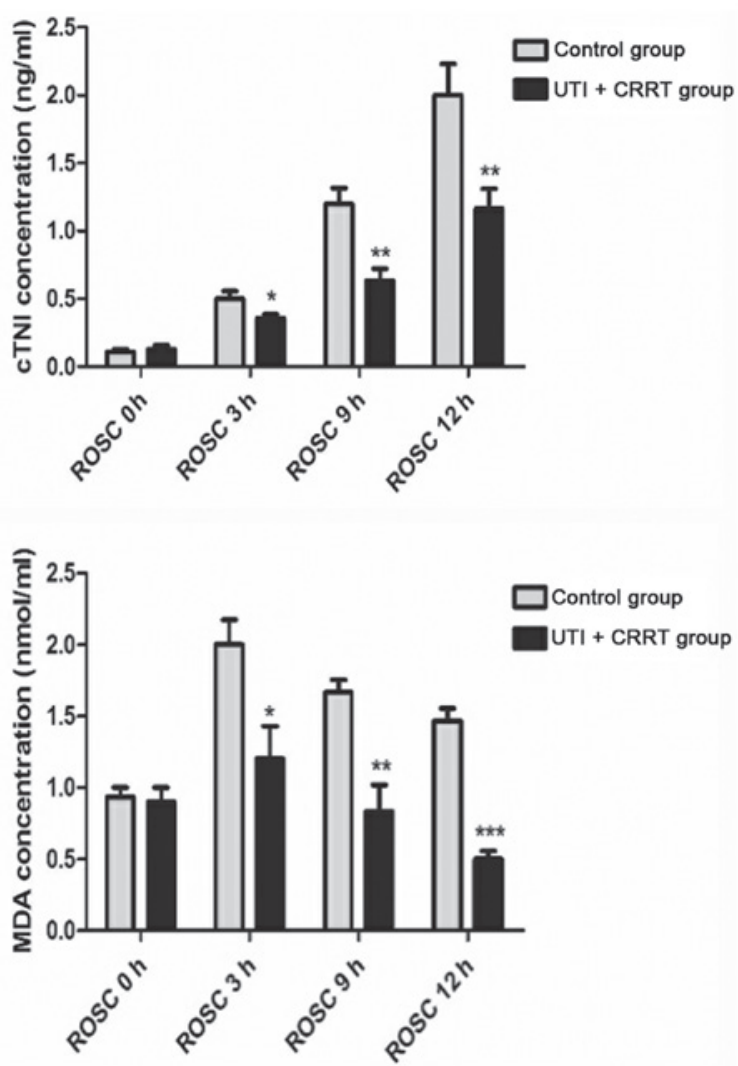

Figure 1. Serum expression of cTnI and plasma. After CPR, cTnI in the blood of the two groups continued to increase, and MDA peaked at $3 \mathrm{~h}$ after ROSC. The expression of cTnI and MDA in UTI + CRRT group was significantly lower than that in control group from ROSC $3 \mathrm{~h}$. UTI + CRRT vs. control group, ${ }^{*} \mathrm{P}<0.05,{ }^{* *} \mathrm{P}<0.01,{ }^{* * *} \mathrm{P}<0.001$. cTnI, cardiac troponin I; CPR, cardiopulmonary resuscitation; MDA, malondialdehyde; UTI, ulinastatin; CRRT, continuous renal replacement theraphy; ROSC, return of spontaneous circulation.

GTCTAGAGCATCATC-3'; downstream 5'-GAGAAATGAG GAAGTAAGGG-3'; internal reference GAPDH: Upstream 5'-AGGTCGGTGTGAACGGATTTG-3'; downstream 5'-TGTAGACCATGTAGTTGAGGTCA-3'. The relative expression level of each index is $2-\Delta \mathrm{Cq}[\Delta \mathrm{Cq}=\mathrm{Cq}$ (target gene) - Cq (GAPDH)].

Statistical analysis. The results were analyzed using GraphPad Prism software (Version 5.01; GraphPad Software, Inc., San Diego, Chile). The differences of the indicators between the two groups were compared by independent sample t-test. The expression of each indicator at four time points was measured using the variance analysis of repeated measurements. A $\mathrm{P}<0.05$ was considered to indicate a statistically significant difference.

\section{Results}

The basic physiological variables of the control and the experimental group. There was no significant difference in body temperature, heart rate, mean arterial pressure, cardiac defibrillation and basic life support between the two groups $(\mathrm{P}>0.05)$ (Table I).

Evaluation of the difference between the biochemical indicators at different time points between the two groups of 
Table I. Baseline physiology and resuscitation related variables (mean $\pm \mathrm{SD}$ ).

\begin{tabular}{lccc}
\hline Item & $\begin{array}{c}\text { Control } \\
(\mathrm{n}=35)\end{array}$ & $\begin{array}{c}\text { UTI + CRRT } \\
(\mathrm{n}=35)\end{array}$ & t-test \\
\hline Age & $46.54 \pm 7.62$ & $48.02 \pm 9.33$ & 2.473 \\
Sex & & & 0.883 \\
Male & 17 & 19 & 3.234 \\
Female & 18 & 16 & 3.667 \\
Body temperature $\left({ }^{\circ} \mathrm{C}\right)$ & $37.7 \pm 0.4$ & $37.5 \pm 0.6$ & 0.968 \\
HR (times/min) & $263 \pm 20$ & $270 \pm 22$ & 0.889 \\
MAP (mm/Hg) & $85 \pm 9$ & $87 \pm 11$ & 0.802 \\
DF (times) & $3 \pm 1$ & $3 \pm 1$ & 0.694 \\
BLS (min) & $3.7 \pm 2.0$ & $3.6 \pm 1.8$ & 0.753 \\
\hline
\end{tabular}

HR, heart rate; MAP, mean arterial pressure; DF, cardiac defibrillation; BLS, basic life support; SD, standard deviation.

Table II. Comparison of biochemical indicators in two groups (mean \pm SD).

\begin{tabular}{|c|c|c|c|c|c|c|c|}
\hline \multirow[b]{2}{*}{ Groups } & \multirow[b]{2}{*}{ Index } & \multicolumn{6}{|c|}{ ROSC } \\
\hline & & $0 \mathrm{~h}$ & $3 \mathrm{~h}$ & $6 \mathrm{~h}$ & $12 \mathrm{~h}$ & F-value & $\mathrm{P}$-value \\
\hline $\begin{array}{l}\text { Control } \\
(n=35)\end{array}$ & $\begin{array}{l}\mathrm{pH} \\
\mathrm{SaO}_{2}(\%) \\
\mathrm{HCO}_{3}^{-} \\
(\mathrm{mmol} / \mathrm{l}) \\
\mathrm{Lac}(\mathrm{mmol} / \mathrm{l})\end{array}$ & $\begin{array}{c}7.25 \pm 0.04 \\
94 \pm 2 \\
34 \pm 3 \\
7.46 \pm 2.15\end{array}$ & $\begin{array}{c}7.26 \pm 0.05 \\
94 \pm 3 \\
30 \pm 3 \\
6.04 \pm 2.02\end{array}$ & $\begin{array}{c}7.28 \pm 0.07 \\
93 \pm 4 \\
27 \pm 4 \\
5.53 \pm 2.68\end{array}$ & $\begin{array}{c}7.25 \pm 0.04 \\
93 \pm 3 \\
23 \pm 5 \\
3.92 \pm 2.66\end{array}$ & $\begin{array}{l}1.352 \\
1.023 \\
0.420 \\
0.524\end{array}$ & $\begin{array}{l}0.236 \\
0.991 \\
0.621 \\
0.268\end{array}$ \\
\hline $\begin{array}{l}\text { CRRT + UTI } \\
\text { group }(n=35)\end{array}$ & $\begin{array}{l}\mathrm{pH} \\
\mathrm{SaO}_{2}(\%) \\
\mathrm{HCO}_{3}^{-} \\
(\mathrm{mmol} / \mathrm{l}) \\
\mathrm{Lac}(\mathrm{mmol} / \mathrm{l})\end{array}$ & $\begin{array}{c}7.24 \pm 0.04 \\
95 \pm 3 \\
34 \pm 4 \\
7.51 \pm 2.42\end{array}$ & $\begin{array}{c}7.25 \pm 0.06 \\
94 \pm 4 \\
25 \pm 4^{\mathrm{a}} \\
4.06 \pm 1.83^{\mathrm{a}}\end{array}$ & $\begin{array}{c}7.26 \pm 0.08 \\
95 \pm 4 \\
19 \pm 5^{\mathrm{b}} \\
3.08 \pm 1.7^{\mathrm{a}}\end{array}$ & $\begin{array}{c}7.24 \pm 0.05 \\
93 \pm 4 \\
17 \pm 4^{\mathrm{a}} \\
2.74 \pm 1.50^{\mathrm{a}}\end{array}$ & $\begin{array}{l}1.0839 \\
0.832 \\
7.453 \\
6.883\end{array}$ & $\begin{array}{l}0.738 \\
0.651 \\
0.0326 \\
0.0192\end{array}$ \\
\hline
\end{tabular}

UTI + CRRT vs. control group, ${ }^{\mathrm{a}} \mathrm{P}<0.05,{ }^{\mathrm{b}} \mathrm{P}<0.01$. ROSC, return of spantaneous circulation; Lac, lactic acid; CRRT, continuous renal replacement theraphy; UTI, ulinastatin; SD, standard deviation.

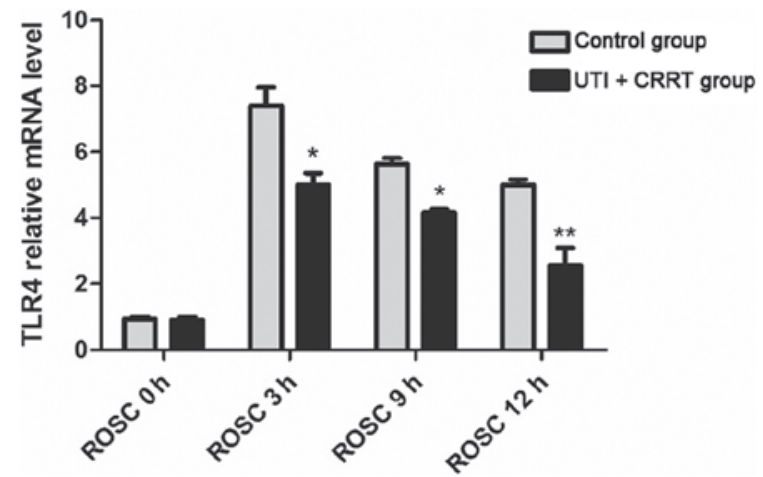

Figure 2. RT-PCR detection of TLR4 mRNA levels. The patient's TLR4 mRNA expression reached the peak $3 \mathrm{~h}$ after the CPR, and then decreased. The expression levels of TLR4 mRNA in the CRRT + UTI were lower than those in the control group at four time points $(0 \mathrm{~h}, 3 \mathrm{~h}, 9 \mathrm{~h}$ and ROSC $12 \mathrm{~h})(\mathrm{P}<0.05)$. UTI + CRRT vs. control group, ${ }^{*} \mathrm{P}<0.05,{ }^{* *} \mathrm{P}<0.01$. RT-PCR, reverse transcription-polymerase chain reaction; TLR4, toll-like receptor 4 ; $\mathrm{CPR}$, cardiopulmonary resuscitation; CRRT, continuous renal replacement therapy; UTI, ulinastatin; ROSC, return of spontaneous circulation. patients. The levels of $\mathrm{pH}$ and $\mathrm{SaO}_{2}$ in the two groups were not significantly different at any time point $(\mathrm{P}>0.05)$. Compared with the control group, the levels of $\mathrm{HCO}_{3}{ }^{-}$and $\mathrm{LAC}$ in the CRRT + UTI group was downregulated significantly at $3 \mathrm{~h}$ after ROSC (Table II).

Serum cTnI and plasma MDA expression. After CPR, the cTnI in the blood of the two groups showed a continuous upward trend, and MDA reached the peak at $3 \mathrm{~h}$ of ROSC. Starting from ROSC $3 \mathrm{~h}$, UTI combined with CRRT significantly reduced the expression of $\mathrm{cTnI}$ and MDA $(\mathrm{P}<0.05)$ (Fig. 1).

RT-PCR detection of TLR4 mRNA levels. The patient's TLR4 mRNA expression reached the peak $3 \mathrm{~h}$ after the CPR, and then decreased. The expression levels of TLR4 mRNA in the CRRT + UTI group were lower than those in the control group at four time points $(0,3,9$, and ROSC $12 \mathrm{~h})(\mathrm{P}<0.05)$ (Fig. 2). 
Table III. The time of recovery of consciousness and spontaneous breathing (h) (mean \pm SD).

\begin{tabular}{lcccc}
\hline Groups & $\mathrm{n}$ & $\begin{array}{c}\text { Average recovery time } \\
\text { of spontaneous breathing }\end{array}$ & $\begin{array}{c}\text { Average recovery time } \\
\text { of consciousness }\end{array}$ & P-value \\
\hline Control & 35 & $15 \pm 7.2$ & $52 \pm 12.5^{\mathrm{a}}$ & $36 \pm 11.2$ \\
CRRT + UTI & 35 & $33 \pm 8.5^{\mathrm{b}}$ & 2.604 & 0.0204
\end{tabular}

UTI + CRRT vs. control group, ${ }^{\mathrm{a} P}<0.05,{ }^{\mathrm{b}} \mathrm{P}<0.01$. CRRT, continuous renal replacement theraphy; UTI, ulinastatin; SD, standard deviation .

Table IV. APACHE II score (mean $\pm \mathrm{SD})$.

APACHE II score (points)

\begin{tabular}{lllr}
\cline { 2 - 4 } Groups & $\mathrm{n}$ & Before & After \\
\hline Control & 35 & $24.41 \pm 4.41$ & $21.34 \pm 6.23$ \\
UTI + CRRT & 35 & $24.57 \pm 5.34$ & $16.60 \pm 8.49^{\mathrm{a}}$
\end{tabular}

UTI + CRRT vs. control group, ${ }^{\mathrm{a}} \mathrm{P}<0.01$. CRRT, continuous renal replacement theraphy; UTI, ulinastatin; SD, standard deviation.

Detection of the expression of IL- 6 and TNF- $\alpha$ by ELISA. After CPR, the levels of IL- 6 and TNF- $\alpha$ in the blood of the two groups reached the peak at $9 \mathrm{~h}$ and $3 \mathrm{~h}$ of ROSC, respectively. However, the levels of IL- 6 and TNF- $\alpha$ in UTI + CRRT were significantly lower than those in the control group $(\mathrm{P}<0.05)$ (Fig. 3).

Average recovery time of consciousness and spontaneous breathing after $C P R$. The average recovery time of consciousness and spontaneous breathing for the patients in UTI combined with CRRT was significantly shorter than the control group $(\mathrm{P}<0.05)$ (Table III).

APACHE II score of two groups. APACHE II scores were assessed by designated physicians before and $24 \mathrm{~h}$ after CPR. UTI combined with CRRT significantly reduced APACHE II scores (Table IV).

\section{Discussion}

After CA occurs in patients, it can lead to various pathological situations, such as inflammation, oxidative stress, myocardial damage and heart damage. In the present study, we analyzed multiple biomarkers at multiple time points after CPR treatment, including cTnI, MDA, TLR4, TNF- $\alpha$, and IL-6. CTnI is a specific marker of myocardial injury (11). Early myocardial injury can be detected by serum cTnI levels (12). In the present study, serum cTnI was continuously elevated in both groups, but the level of UTI + CRRT was significantly lower than that of the control group. Changes in cTnI suggest that CA will inevitably lead to myocardial injury in patients, but the use of UTI + CRRT can reduce the damage to a certain extent.

It has been shown that oxidative stress is associated with lipid peroxidation and is one of the mechanisms of neuronal injury induced by ischemia-reperfusion $(13,14)$. MDA, as the final product of lipid oxidation, can cause
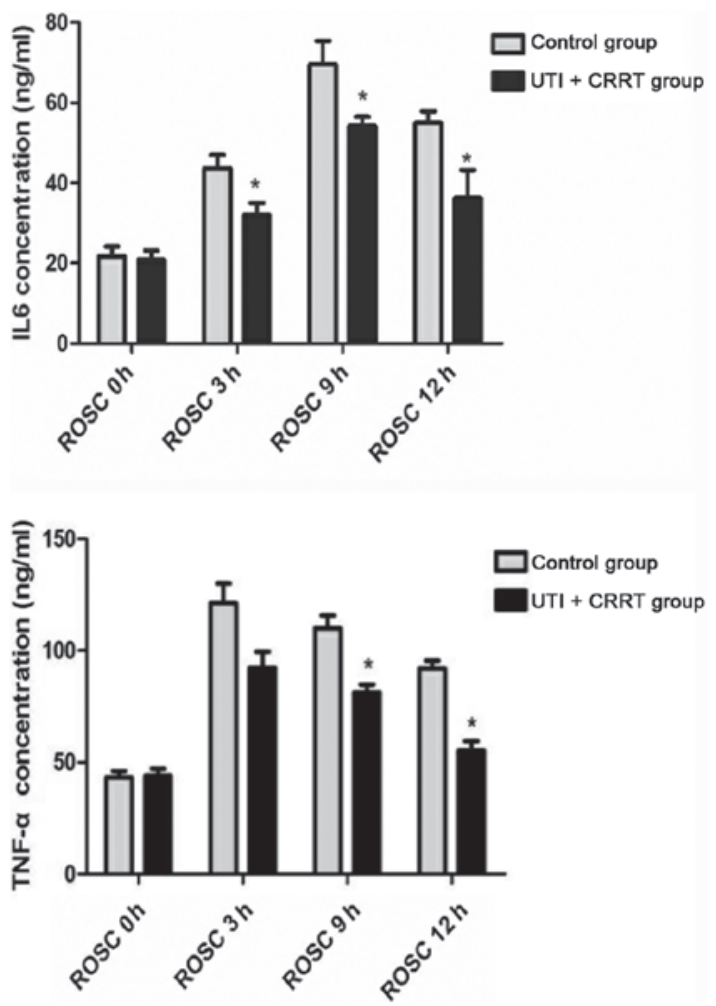

Figure 3. ELISA detection of IL-6, and TNF- $\alpha$ expression. After CPR, the levels of IL- 6 and TNF- $\alpha$ in the blood of the two groups reached the peak at $9 \mathrm{~h}$ and $3 \mathrm{~h}$ of ROSC, respectively. However, the levels of IL- 6 and TNF- $\alpha$ in UTI + CRRT group were significantly lower than those in control group. UTI + CRRT group vs. control group, ${ }^{*} \mathrm{P}<0.05$. TNF- $\alpha$, tumor necrosis factor- $\alpha$; IL-6, interleukin-6, CPR, cardiopulmonary resuscitation; ROSC, return of spontaneous circulation; UTI, ulinastatin; CRRT, continuous renal replacement theraphy.

cross-linked polymerization of protein, nucleic acid and other macromolecules, and has cytotoxicity, it is often used as a marker of oxidative stress after ischemia-reperfusion $(15,16)$. In 
the present study, plasma MDA levels in both groups increased significantly, reached a peak at $3 \mathrm{~h}$ after CPR treatment, and combination of UTI + CRRT significantly decreased MDA content, indicating that UTI and CRRT have protective effects on myocardium after CPR.

Organ damage CA after successful CRP is considered to associate with systemic inflammatory response; various cytokines and lipopolysaccharide (LPS) levels have been proved to have risen significantly in patients with successful resuscitation $(17,18)$. TLR4 recognizes LPS, which promotes the production of a variety of inflammatory cytokines (IL-6 and TNF- $\alpha$ ), leading to sepsis-like syndrome (19). Activated TLR4 promotes nuclear factor expression during cerebral ischemia and hypoxia, and induces the production of cytokines such as TNF- $\alpha$ and IL-6, causing inflammation and nerve damage (20). Therefore, we speculate that TLR4 signaling pathway may inhibit the inflammatory response and nerve damage by hypoxic preconditioning, thus protecting brain function. In addition, previous studies have shown that UTI can reduce lung and kidney damage caused by LPS inhibiting the inflammatory response of these organs (21). In this study, TLR4 gene was significantly upregulated in both groups after CPR, and TNF- $\alpha$ and IL- 6 were also upregulated. UTI combined with CRRT significantly lowered these indicators and shortened the recovery time of consciousness and spontaneous breathing, reduced the APACHE II score.

In conclusion, we found that UTI combined with CRRT can protect against ischemia/reperfusion injury caused by early CPR, and can inhibit the inflammatory response induced by TLR4 after early CPR.

\section{References}

1. Zhang S: Sudden cardiac death in China: Current status and future perspectives. Europace 17: 14-18, 2015.

2. de Vreede-Swagemakers JJ, Gorgels AP, Dubois-Arbouw WI, van Ree JW, Daemen MJ, Houben LG and Wellens HJ: Out-of-hospital cardiac arrest in the 1990's: A population-based study in the Maastricht area on incidence, characteristics and survival. J Am Coll Cardiol 30: 1500-1505, 1997.

3. Peters R and Boyde M: Improving survival after in-hospital cardiac arrest: The Australian experience. Am J Crit Care 16: 240-246, 2007

4. Kim RJ, Wu E, Rafael A, Chen EL, Parker MA, Simonetti O, Klocke FJ, Bonow RO and Judd RM: The use of contrast-enhanced magnetic resonance imaging to identify reversible myocardial dysfunction. N Engl J Med 343: 1445-1453, 2000.

5. Carden DL and Granger DN: Pathophysiology of ischaemia-reperfusion injury. J Pathol 190: 255-266, 2000.

6. Hernandez LA and Grisham MB: Role of neutrophils in ischemia reperfusion induced microvascular injury. Am J Physiol Heart Circ Physiol 3: 699-703, 2006.

7. Hausenloy DJ and Yellon DM: Myocardial ischemia-reperfusion injury: A neglected therapeutic target. J Clin Invest 123: 92-100, 2013

8. Koga Y, Fujita M, Tsuruta R, Koda Y, Nakahara T, Yagi T, Aoki T, Kobayashi C, Izumi T, Kasaoka S, et al: Urinary trypsin inhibitor suppresses excessive superoxide anion radical generation in blood, oxidative stress, early inflammation, and endothelial injury in forebrain ischemia/reperfusion rats. Neurol Res 32: 925-932, 2010.
9. Wang G, Wen J, Wilbur RR, Wen P, Zhou SF and Xiao X: The effect of somatostatin, ulinastatin and Salvia miltiorrhiza on severe acute pancreatitis treatment. Am J Med Sci 346: 371-376, 2013.

10. Pang XY, Fang CC, Chen YY, Liu K and Song GM: Effects of ulinastatin on perioperative inflammatory response and pulmonary function in cardiopulmonary bypass patients. Am J Ther 23: e1680-e1689, 2016.

11. Kruzan RM,Herzog CA, Wu A, Sang Y,Parekh RS, Matsushita K, Hwang S, Cheng A, Coresh J, Powe NR, et al: Association of NTproBNP and cTnI with outpatient sudden cardiac death in hemodialysis patients: The choices for healthy outcomes in caring for ESRD (CHOICE) study. BMC Nephrol 17: 18, 2016.

12. Hu CL, Wei HY, Liu ZY, Li X, Liao XX, Li YJ, Zhan H, Jing XL, Xiong Y, Liu YY, et al: Investigation of the relationship between venticular fibrillation duration and cardiac/neurological damage in a rabbit model of electrically induced arrhythmia. J Trauma 69: 1442-1447, 2010.

13. Murdolo G, Piroddi M, Luchetti F, Tortoioli C, Canonico B, Zerbinati $\mathrm{C}$, Galli $\mathrm{F}$ and Iuliano L: Oxidative stress and lipid peroxidation by-products at the crossroad between adipose organ dysregulation and obesity-linked insulin resistance. Biochimie 95: 585-594, 2013.

14. Martindale JJ and Metzger JM: Uncoupling of increased cellular oxidative stress and myocardial ischemia reperfusion injury by directed sarcolemma stabilization. J Mol Cell Cardiol 67: 26-37, 2014.

15. Li XY and Chow CK: An improved method for the measurement of malondialdehyde in biological samples. Lipids 29: 73-75, 1994.

16. Esterbauer H, Schaur RJ and Zollner H: Chemistry and biochemistry of 4-hydroxynonenal, malonaldehyde and related aldehydes. Free Radic Biol Med 11: 81-128, 1991.

17. Neumar RW, Nolan JP, Adrie C, Aibiki M, Berg RA, Böttiger BW, Callaway C, Clark RS, Geocadin RG, Jauch EC, et al: Post-cardiac arrest syndrome: Epidemiology, pathophysiology, treatment, and prognostication. A consensus statement from the International Liaison Committee on Resuscitation (American Heart Association, Australian and New Zealand Council on Resuscitation, European Resuscitation Council, Heart and Stroke Foundation of Canada, InterAmerican Heart Foundation, Resuscitation Council of Asia, and the Resuscitation Council of Southern Africa); the American Heart Association Emergency Cardiovascular Care Committee; the Council on Cardiovascular Surgery and Anesthesia; the Council on Cardiopulmonary, Perioperative, and Critical Care; the Council on Clinical Cardiology; and the Stroke Council. Circulation 118: 2452-2483, 2008.

18. Erenler AK, Çelik S, Baydin A, Tomak L, KoSargelir M and Yasti AÇ: Outcomes of cardiopulmonary resuscitation in trauma patients in the emergency department. Eur Rev Med Pharmacol Sci 19: 2567-2571, 2015.

19. Janssen E, Ozcan E, Liadaki K, Jabara HH, Manis J, Ullas S, Akira S, Fitzgerald KA, Golenbock DT and Geha RS: TRIF signaling is essential for TLR4-driven IgE class switching (IRM5P. 707). J Immunol 192: 2651-2658, 2014.

20. Blanco AM, Vallés SL, Pascual M and Guerri C: Involvement of TLR4/type I IL-1 receptor signaling in the induction of inflammatory mediators and cell death induced by ethanol in cultured astrocytes. J Immunol 175: 6893-6899, 2005.

21. Chen J, Wang J, Su C, Qian W, Sun L, Sun H, Chen J, Zhang H and Zhang J: Urinary trypsin inhibitor attenuates LPS-induced endothelial barrier dysfunction by upregulation of vascular endothelial-cadherin expression. Inflamm Res 65: 213-224, 2016. 